\title{
Strong Role of Calcination Temperature for Improving Magnetocaloric Effect in Nd0.5Sr0.5MnO3 Prepared via Combustion Technique
}

mahmoud Aly Hamad ( $\nabla$ m_hamad76@yahoo.com )

Al-Jouf University https://orcid.org/0000-0002-1863-0276

Hatem R. Alamri

Umm Al-Qura University

\section{Research Article}

Keywords: Phenomenological model, Magnetocaloric effect, Nd0.5Sr0.5MnO3

Posted Date: July 15th, 2021

DOI: https://doi.org/10.21203/rs.3.rs-703487/v1

License: (c) (i) This work is licensed under a Creative Commons Attribution 4.0 International License.

Read Full License 


\title{
Strong role of calcination temperature for improving magnetocaloric effect in $\mathrm{Nd}_{0.5} \mathrm{Sr}_{0.5} \mathrm{MnO}_{3}$ prepared via combustion technique
}

\author{
Mahmoud A. Hamad ${ }^{1, *}$, and Hatem R. Alamri ${ }^{2}$ \\ ${ }^{1}$ King Marriott Academy, Alexandria, Egypt \\ 2 Physics Department, Aljamoum University College, Umm Al-Qura University, \\ Makkah 21955, Saudi Arabia
}

\begin{abstract}
In this work, phenomenological model $(\mathrm{PM})$ is used to simulate the magnetocaloric effect (MCE) of $\mathrm{Nd}_{0.5} \mathrm{Sr}_{0.5} \mathrm{MnO}_{3}$ (NSMO) sample synthesized at various values of temperature of calcination $\left(\mathrm{T}_{\text {cal }}\right)$. The results showed that MCE of NSMO samples depends strongly on $\mathrm{T}_{\text {cal }}$, achieving that a conventional MCE for nanocrystalline NSMO samples. However, the thermomagnetic behavior of bulk NSMO sample NSMO contains both conventional MCE and inverse MCE. MCE of NSMO improves powerfully with increasing $\mathrm{T}_{\text {cal }}$. The calcination process is concluded as a powerful tool for improving MCE for NSMO. Especially, NSMO parameters in MCE of some published works are better, with a value equal to or greater than the corresponding MCE parameters in the same value of $\Delta \mathrm{H}$. MCE of NSMO system, particularly for nitrogen and hydrogen liquefaction, covers an excellent temperature range is of interest for MR.
\end{abstract}

Keywords:

Phenomenological model; Magnetocaloric effect; $\mathrm{Nd}_{0.5} \mathrm{Sr}_{0.5} \mathrm{MnO}_{3}$.

\section{*Corresponding author:}

E-mail address: m_hamad76@yahoo.com 


\section{Introduction}

With rapid steps, increased refrigeration efficiency, reduction in weight, greater mechanical stability, lower environmental impact, greater efficiency, lower noise levels and high cost-effectiveness, magnetocaloric refrigerator (MR) has developed into a strong alternative to gas refrigeration by magnetocaloric effect (MCE) [1-6]. In space applications, medical appliances, aerospace applications and food cooling, MR is a fundamental requirement [7-14]. In the range of temperatures near the temperature of a magnetic phase transition $\left(T_{M P T}\right)$, MR uses the idea to apply MCE on magnetocaloric (MC) material [15-20]. The researchers looked into a variety of magnet materials, such as magnetic alloys, manganites and others in order to develop and improve MR [29-34]. In traditional MCE, a reaction of adiabatic demagnetization occurs as the cooling action in MC material, which is carried out with sudden removal of $\mathrm{H}_{\mathrm{exe}}$ [35-37]. Quite opposite way, adiabatic magnetization can cool MC materials that increases by sudden increasing $\mathrm{H}_{\mathrm{exe}}$ applied on MC materials. It is referred to as an inverse MCE [38]. In antiferromagnetic (AFM) materials, this inverse MCE is obvious over AFM transition temperature range.

The unusual magnetic arrangement such as AFM and spinal orientation leads to a highly interesting study of the rare earth-manganites [39-41]. 
These types of manganese have significant electronic, electrical and magnetic properties such as colossal magnetoresistance of ferromagnetic and antiferromagnetic, negligible eddy current, semiconducting, metallic and insulating states related to ferromagnetic and antiferromagnetic ordering [39-41]. They also showed great promise as electronic equipment materials, solid oxides fuel cells, magnetoresistive, infrared detectors, magnetic recording devices, and radiometers [42, 43]. Chen et al. discovered a large $\Delta \mathrm{S}_{\mathrm{M}}$ of $7.5 \mathrm{~J} / \mathrm{kg} . \quad \mathrm{K}$ in polycrystalline $\mathrm{Nd} 0: 5 \mathrm{Sr} 0: 5 \mathrm{MnO} 3$ (prepared by the sol-gel) under $\mathrm{H}_{\text {exe }}$ of $1 \mathrm{~T}$ at the charge-ordered state transition temperature [44]. Liu et al. succeed in tailoring MCE of $\mathrm{Nd}_{0.5} \mathrm{Sr}_{0.5} \mathrm{MnO}_{3}$ (NSMO) epitaxial films via controlling the lattice-mismatch-induced-strain [45]. Sande et al. reported that the amount of $\left|\Delta S_{M}\right|$ of NSMO around this first-order transition is around three times larger than that obtained around the second-order transition (ferromagnetic-metallic-to-paramagnetic-insulator) in the same sample [46]. Xu et al. prepared NSMO nanoparticles via sol-gel method, observing the coexistence of an inverse MCE and a conventional MCE, depending on particle size [47]. Venkatesh et al. used the floating zone methodology to grow single NSMO crystals, revealing that the value of $\Delta S_{M}$ is found to be much higher than $\Delta S_{M}$ reported in polycrystalline ones [48]. Shankar et al. investigated bulk 
and nanocrystalline NSMO ceramic samples were prepared via the combustion technique and calcined at various temperatures showing broadly second order ferromagnetic-paramagnetic phase transitions for all samples beside antiferromagnetic-paramagnetic phase transition for bulk sample [49]. Since, the powder of NSMO was divided into several parts and calcined at $600^{\circ} \mathrm{C}, 900^{\circ} \mathrm{C}$, and $1300^{\circ} \mathrm{C}$ for $6 \mathrm{~h}$ to obtain the samples of various particle sizes, labeling by C600, C900, and C1300, respectively, in this research. From this practical point, the MCE of NSMO samples is recommended to be investigated in this work. In this research, phenomenological model (PM) is used to study the thermomagnetic properties through the work of simulated magnetization temperature curves for NSMO, concluding $\Delta S_{M}$, heat capacity change $\left(\Delta C_{P, H}\right)$, and relative cooling power $(\mathrm{RCP})$.

\section{Theoretical Considerations}

According to $\mathrm{PM}$, the magnetization $(M)$ vs. temperature $(T)$ is provided by $[50,51]$ :

$$
M(T)=\left(\frac{M_{i}-M_{f}}{2}\right)\left[\tanh \left(\alpha\left(T_{M F T}-T\right)\right)\right]+\beta\left(T-T_{M F T}\right)+\left(\frac{M_{i}+M_{f}}{2}\right),
$$


where $M_{i}$ is an initial value of magnetization at ferromagnetic (FM) or AFM-paramagnetic transition and $M_{f}$ is a final value of this transition as shown in Fig. 1, where $\alpha=\frac{2(\beta-\gamma)}{M_{i}-M_{f}}$,

$$
\beta=\left(\frac{d M}{d T}\right)_{\text {average }} \text { for FM or AFM phase, and } \gamma=\left(\frac{d M}{d T}\right)_{T=T_{M F T}} .
$$

\section{Results and Discussion}

To simulate MCE of NSMO, PM parameters for NSMO were directly determined from experimental data (magnetization vs. temperature), as described in Ref. [49]. Fig. 2 depicts the magnetization vs. temperature for the bulk (C1300) and nanocrystalline (C600) and (C900) NSMO samples measured at $0.05 \mathrm{~T}$, with the experimental data from Ref. [49] represented by symbols and the simulated data represented by dashed lines. According to Fig. 2, there is a satisfactory agreement between the experimental and theoretical values of $\mathrm{M}(\mathrm{T})$ for NSMO samples under $0.05 \mathrm{~T}$, indicating that PM is a suitable model for fitting magnetization vs. temperature for FM-paramagnetic and AFM transitions.

Interestingly, it is expecting the existence of an inverse MCE plus conventional MCE for $\mathrm{C} 1300$ sample as we will show later. 
$\Delta S_{M}$ of NSMO samples under adiabatic magnetic field shift $(\Delta \mathrm{H})$ of 0.05 $\mathrm{T}$ is formulated by

$$
\Delta S_{M}(T, \Delta H)=0.05 \times\left(-\alpha \times\left(\frac{M_{i}-M_{f}}{2}\right) \times \operatorname{sech}^{2}\left(\alpha \times\left(T_{M P T}-T\right)\right)+\beta\right) .
$$

A maximum of $\Delta S_{M}\left(\Delta \mathrm{S}_{\mathrm{Max}}\right)$ can be determined as follows:

$$
\Delta S_{\operatorname{Max}}=0.05 \times\left(-\alpha \times\left(\frac{M_{i}-M_{f}}{2}\right)+\beta\right)
$$

Fig. 3 shows simulated temperature dependence of $\Delta S_{M}$ for NSMO samples under $\Delta \mathrm{H}$ of $0.05 \mathrm{~T}$, calculated by using Eq. (2). Interestingly, $\Delta S_{M}$ of NSMO depends strongly on temperature of calcination $\left(\mathrm{T}_{\text {cal }}\right)$, concluding that the thermomagnetic behavior of NSMO characterizes as a conventional MCE over investigated range of temperatures for nanocrystalline (C600) and (C900) NSMO samples. However, the thermomagnetic behavior of NSMO characterizes as an inverse MCE of bulk (C1300) NSMO sample as the result of FM to AFM transition below the temperature of FM to AFM transition $\left(\mathrm{T}_{\mathrm{N}} \sim 225 \mathrm{~K}\right)$. But, above $\mathrm{T}_{\mathrm{N}}$, the thermomagnetic behavior of NSMO characterizes as a conventional MCE with negative value of $\Delta S_{M}$ as result of FM transition. Therefore, C1300 sample can be utilized in MR that exploits both positive and negative magnetic entropy changes via magnetization and demagnetization processes, respectively. With increase $\mathrm{T}_{\text {cal }},\left|\Delta \mathrm{S}_{\mathrm{Max}}\right|$ is enhanced strongly due to increase particle size of NSMO. This increase particle size of 
NSMO leads to bigger crystallite size, leads to decrease the possibility of creating of spin disorder in the surface.

An effectiveness for NSMO samples as MC material can be evaluated by RCP. This parameter is accounted by the absolute value of $\Delta \mathrm{S}_{\mathrm{Max}}$ and full-width at half-maximum ( $\left.\delta \mathrm{T}_{\mathrm{FWHM}}\right)$ of the $\Delta \mathrm{S}_{\mathrm{M}}$ curve by following formula:

$\mathrm{RCP}=\left|\Delta S\left(T, H_{\text {max }}\right)\right|_{M a x} \times \delta \mathrm{T}_{\text {FWнм }}$,

where $\delta \mathrm{T}_{\text {ғшнм }}$ can be obtained as follows

$$
\delta \mathrm{T}_{\mathrm{FWHM}}=\frac{2}{\alpha} \times \cosh ^{-1}\left(\sqrt{\frac{2\left(M_{i}-M_{f}\right) \times \alpha}{\left(M_{i}-M_{f}\right) \times \alpha+2 \beta}}\right)
$$

Table I indicates that $\delta \mathrm{T}_{\text {гWнм }}$ has significant values and are ranged between 44 and $171 \mathrm{~K}$ for NSMO samples under $\Delta \mathrm{H}$ of $0.05 \mathrm{~T}$. Furthermore, RCP changes nonmonotonically with $\mathrm{T}_{\text {cal }}$ as a result of competition between $\delta \mathrm{T}_{\mathrm{FWHM}}$ and $\Delta \mathrm{S}_{\mathrm{M}}$ with $\mathrm{T}_{\text {cal }}$.

According PM model [50], the characterization of $\Delta C_{P, H}$ curves for NSMO samples is expected as follows

$$
\Delta C_{P, H}=-0.05 \alpha^{2} \times T \times\left(M_{i}-M_{f}\right) \times \tanh \left(\alpha \times\left(T_{M P T}-T\right)\right) \operatorname{sech}^{2}\left(\alpha \times\left(T_{M P T}-T\right)\right) .
$$

Fig. 4 shows simulated $\Delta \mathrm{C}_{\mathrm{P}, \mathrm{H}}$ vs. temperature for NSMO samples under $\Delta \mathrm{H}$ of $0.05 \mathrm{~T}$. For C600 and C600 samples, the simulated $\Delta C_{P, H}$ varies from negative value to positive one as a result of FM transition. 
For C1300 sample, the simulated $\Delta C_{P, H}$ varies from positive value to negative one over range of AFM transition. However, the inversed characterization is observed when over range of FM transition.

To investigate extra details about MCE in NSMO samples, the refrigerant capacity (RC) is well-thought-out to judge the efficiency for NSMO samples as effective MC materials in MR. RC was calculated as follows [51]

$$
R C=\int_{T_{C}-\frac{\delta T_{\mathrm{FWHM}}}{2}}^{T_{C}+\frac{\delta \mathrm{T}_{\mathrm{FHMM}}}{2}} \Delta S_{M} d T .
$$

Form Table I, RC takes the same behavior of RCP due to the same reasons.

Table II offers a comparative image of MCE parameters of NSMO samples with corresponding ones of several MC materials in same value of $\Delta \mathrm{H}$ and higher ones in published works [52-55]. Importantly, the MCE parameters of NSMO samples are higher or as good as corresponding MCE parameters of these published works in the same value of $\Delta \mathrm{H}$ or larger. Finally, NSMO samples are interesting MC materials in MR below room temperature notably over temperature range of nitrogen and hydrogen liquefaction. Furthermore, the loss of eddy current plus loss of 
hysteresis energy are disregarded due to high resistivity plus small hysteresis [49].

\section{$\underline{\text { Conclusion }}$}

The simulation of MCE is done for NSMO compounds synthesized and calcined at various values of $\mathrm{T}_{\text {cal }}$. The results of this simulation show that this PM is a constructive model for the calculation of thermomagnetic properties for NSMO compounds for both FM-AFM and FM-paramagnetic transitions. The thermomagnetic behaviour of NSMO characterizes as a conventional MCE over investigated range of temperatures for nanocrystalline NSMO samples. However, the thermomagnetic behaviour of bulk NSMO sample NSMO contains conventional MCE and inverse MCE. MCE in NSMO samples is strong tunable with variation of $\mathrm{T}_{\text {cal }}$ during preparation of NSMO samples. Interesting for MR is the NSMO system covering an outstanding temperature range, particularly of liquefaction nitrogen and liquefaction of hydrogen.

\section{$\underline{\text { References }}$}

[1] Hsini, M., Hcini, S. and Zemni, S., J.Supercond. Nov. Magn. 31 (2018) 81.

[2] Wu, B., Zhang, Y., Guo, D., Wang, J., Ren, Z., Ceramics International, 47(2021) 6290-6297.

[3] Massoudi, J., Smari, M., Nouri, K., Dhahri, E., Khirouni, K., Bertaina, S., Bessais, L., RSC Adv. 10 (2020) 34556 
[4] Hosseininejad, S. S., Ehsani, M. H., Esmaeili, S., Ceramics International, 47 (2021) 11536

[5] Alzahrani, B., Hsini, M., Hcini, S., Boudard, M., Dhahri, A., Bouazizi, M. L., J. Low Temp. Phys. 200 (2020) 26-39

[6] El-Sayed, A.H., Hamad, M.A.: J. Supercond. Nov. Magn. 32, 1447 (2019)

[7] R. Kumar, Mater. Today 4 (2017) 5544.

[8] Ewas, A.M.: Ceram. Int. 43, 7660 (2017).

[9] M.A. Hamad, Process. Appl. Ceram. 9 (2015) 11.

[10] M.A. Hamad, Process.Appl.Ceram. 9 (2015) 11.

[11] M. Bourouina, A. Krichene, N. C. Boudjada, M. Khitouni, and W. Boujelben, Ceram. Int. 43 (2017) 8139.

[12] N. Mechi, B. Alzahrani, S. Hcini, M.L. Bouazizi, A. Dhahri, Phase Trans. 91, 559 (2018).

[13] Villa, E., Tomasi, C., Nespoli, A., Passaretti, F., Lamura, G., Canepa, F., J. Mater. Res. Technol. 9 (2020), 2259

[14] Sfifir, I., Koubaa, W., Koubaa, M., Cheikhrouhou, A.: J.Supercond. Nov. Magn. 30, 911 (2017)

[15] Jeddi, M., Gharsallah, H., Bekri, M., Dhahri, E., Hlil, E. K. J.Low Temp.Phys. 198 (2020), 135.

[16] Xiang, N., Xiaodong, J., Chen, X., Li, H., Liang, W., Yingbang, Y., ... \& Sheng-Guo, L., J. Adv. Ceram.10, 385-441 (2021).

[17] Xiang, H., Xing, Y., Dai, F. Z., Wang, H., Su, L., Miao, L., ... \& Zhou, Y., J. Adv. Ceram. 10, 482-492 (2021).

[18] Zhang, K.S., Xue, J.N., Wang, Y.X., Sun, H., Long, Y.: AIP Adv. 8, 048104 (2018) 
[19] Dung, N. T., Pham, Y., Lam, D. S., Van Dang, N., Gamzatov, A. G., Aliev, A. M., ... \& Thanh, T. D., J. Mater. Res. Technol. 9 (2020) 12747

[20] Mohassel, R., Amiri, M., Abbas, A. K., Sobhani, A., Ashrafi, M., Moayedi, H., Salavati-Niasari, M. J. Mater. Res. Technol. 9 (2020), 1720

[21] Puglielli, F., Mussi, V., Cugini, F., Sarzi Amadè, N., Solzi, M., Bennati, C., ... \& Albertini, F., Front. Energy Res. 7 (2020). $150 .$.

[22] Hcini, S., Boudard, M., Dhahri, A., Zemni, S., Bouazizi, M. L. Mater. Res. Express 6 (2019) 066108.

[23] Hussain, I., Khan, S.N., Kim, E.J., Jeon, S.E. and Koo, B.H., Ceram. Int. 44 (2018) 2892.

[24] El-Sayed, A.H., Hamad, M.A.: Phase Trans. 92, 517 (2019)

[25] S. El Kossi, J. Dhahri and E. K. Hlil, RSC Adv. 6 (2016) 63497

[26] Barclay, J., Brooks, K., Cui, J., Holladay, J., Meinhardt, K., Polikarpov, E., \& Thomsen, E., Cryogenics 100 (2019) 69-76.

[27] Dhahri, A., Jemmali, M., Dhahri, E., Valente, M.A., J. Alloy Compd. 638, 221 (2015).

[28] Mandal, K., Das, S. C., Dutta, P., Pramanick, S., Chatterjee, S. , J. Alloys Comp. 822 (2020) 153454.

[29] N. Raghu Ram, M. Prakash, U. Naresh, N. Suresh Kumar, T. Sofi Sarmash, T. Subbarao, R. Jeevan Kumar, G. Ranjith Kumar, K. Chandra Babu Naidu, J.Supercond.Nov.Magn.(2018) 31:19711979

[30] Kokila, I. P., Kumar, P. S., Kanagaraj, M., Paidi, A. K., He, L., Madeswaran, S., Therese, H. A., J. Nanoparticle Res. 22 (2020) 110.

[31] Singh, V., Bag, P., Rawat, R., \& Nath, R., Scientific Reports, 10 (2020) 1-17. 
[32] Barman, A., Chatterjee, S., Dey, J. K., Datta, A., Mukherjee, D., Phys.Rev.B 102 (2020), 054433.

[33] Mandal, P. R., Khan, A., Nath, T. K. J. Appl. Phys.., 128 (2020), 024104.

[34] Jabar, A., Masrour, R., Mounkachi, O., El Moussaoui, H., Hamedoun, M., Benyoussef, A., Hlil, E. K., J.Supercond.Nov.Magn. 32 (2019) 367.

[35] Fkhar, L., Mounkachi, O., El Maalam, K., Hamedoun, M., Mahmoud, A., Boschini, F., ... \& Benyoussef, A., J.Supercond.Nov.Magn. 32 (2019) 3579.

[36] Qian, Y., Ma, X., Si, X., Liu, H., Luo, X., Lin, J., Liu, Y., Physica Scripta, 95 (2020) 065701.

[37] Liu, Y., Zhang, X., Xing, D., Shen, H., Chen, D., Liu, J., Sun, J., J. Alloys Comp. 616 (2014) 184.

[38] Moya, X., Mañosa, L., Planes, A., Aksoy, S., Acet, M., Wassermann, E. F., Krenke, T. Phys.Rev.B, 75 (2007) 184412.

[39] Magesh J., et. al, Appl. Phys. Lett., 2012, 101, 1-4.

[40] Kurbakov, A. I., Ryzhov, V. A., Runov, V. V., Bykov, E. O., Larionov, I. I., Deriglazov, V. V., ... \& Maignan, A., Phys.Rev.B 100 (2019) 184424.

[41] W. S. Ferreira, J. A. Moreira, A. Almeida, M. R. Chaves, J. P. Ara'ujo, J. B. Oliveira, J. M. Machado, D. Silva, M. A. S’a, T. M. Mendonça and P. S. Carvalho, Phys.Rev.B, 2009, 79, 1-10.

[42] W. Li, C. Y. Xiong, L. C. Jia, J. Pu, B. Chi, X. Chen, J. W. Schwank, J. Li, J. Power Sources 284, 272 (2015).

[43] Tang, Y. F., Zhang, A. M., Wu, X. S., Zhai, Z. Y., AIP Advances, 11 (2021) 045029.

[44] Chen, P., \& Du, Y. W., Chinese Journal of Physics, 39 (2001) 357-362. 
[45] Liu, Y., Ma, T., Qiao, K., Li, J., Xiao, A., Wang, J., ... \& Shen, B., Applied Physics Letters, 116 (2020) 082402.

[46] Sande, P., Hueso, L. E., Miguens, D. R., Rivas, J., Rivadulla, F., Lopez-Quintela, M. A., Applied Physics Letters, 79 (2001) 2040.

[47] Xu, S., Shi, Q., Ju, J., Han, Z., Qian, B., Wang, D., ... \& Du, Y., Journal of nanoscience and nanotechnology, 16 (2016) 2042.

[48] Venkatesh, R., Pattabiraman, M., Sethupathi, K., Rangarajan, G., \& Narayana Jammalamadaka, S., Journal of applied physics, 101 (2007) 09C506.

[49] Shankar, U., Pandey, R., \& Singh, A. K., Journal of Applied Physics 123 (2018) 124301.

[50] M.A. Hamad, Phase Trans. 85 (2012) 106

[51] Hamad, M.A.: Int. J. Thermophys. 36, 2748 (2015)

[52] Amirov, A. A., Makoed, I. I., Chaudhari, Y. A., Bendre, S. T., Yusupov, D. M., Asvarov, A. S., Liedienov, N. A., Pashchenko, A. V., J.Supercond.Nov.Magn. 31 (2018) 3283.

[53] A.H. El-Sayed, M.A. Hamad, J.Supercond.Nov.Magn. 31 (2018) 1895.

[54] M.A. Hamad, J.Supercond.Nov.Magn. 26 (2013) 449

[55] Masrour, R., et al., J.Magn.Magn.Mater. 401, 91-95 (2016) 


\section{Figures}

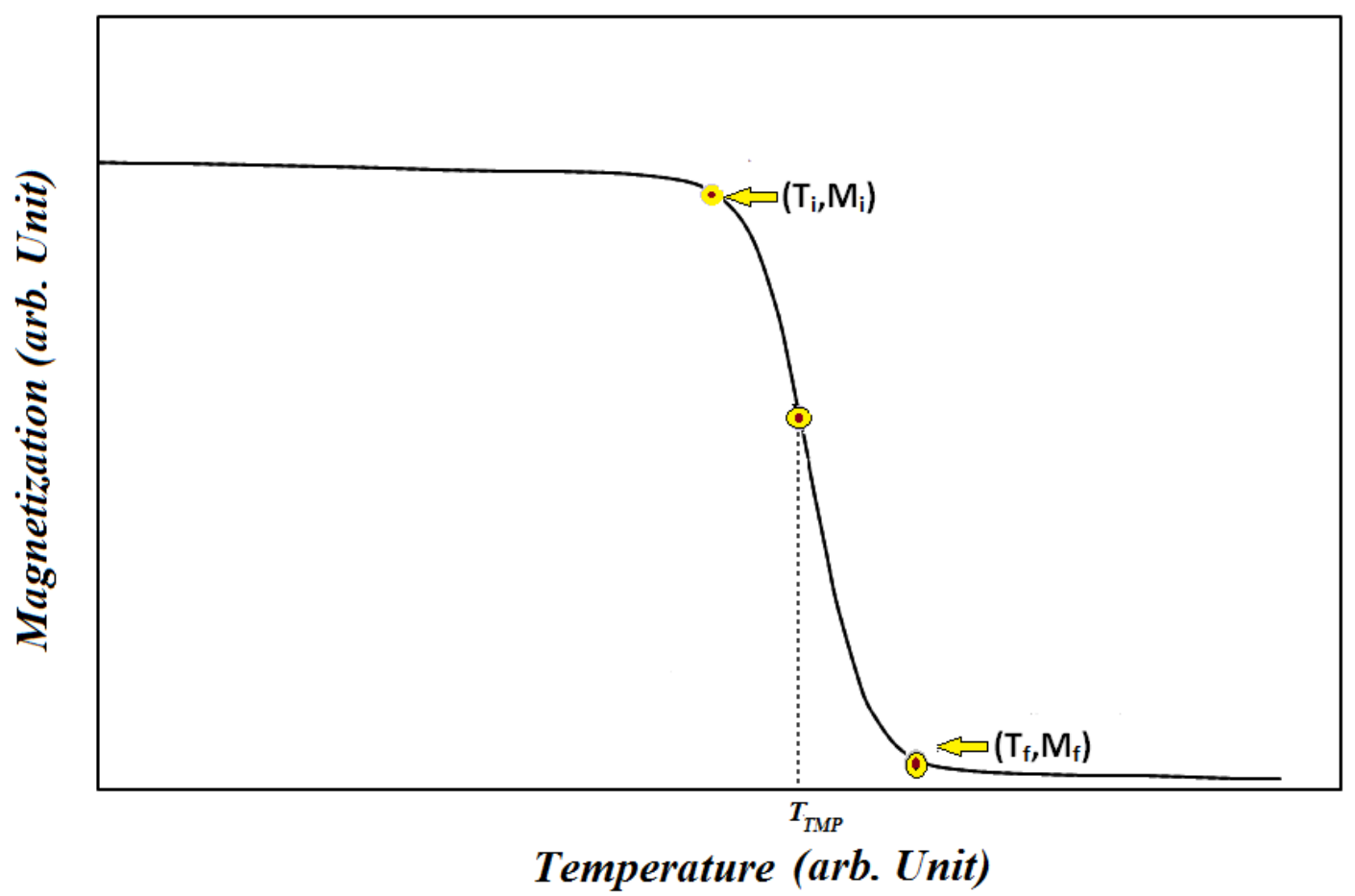

Figure 1: dependence of Isofield magnetization vs. temperature. 

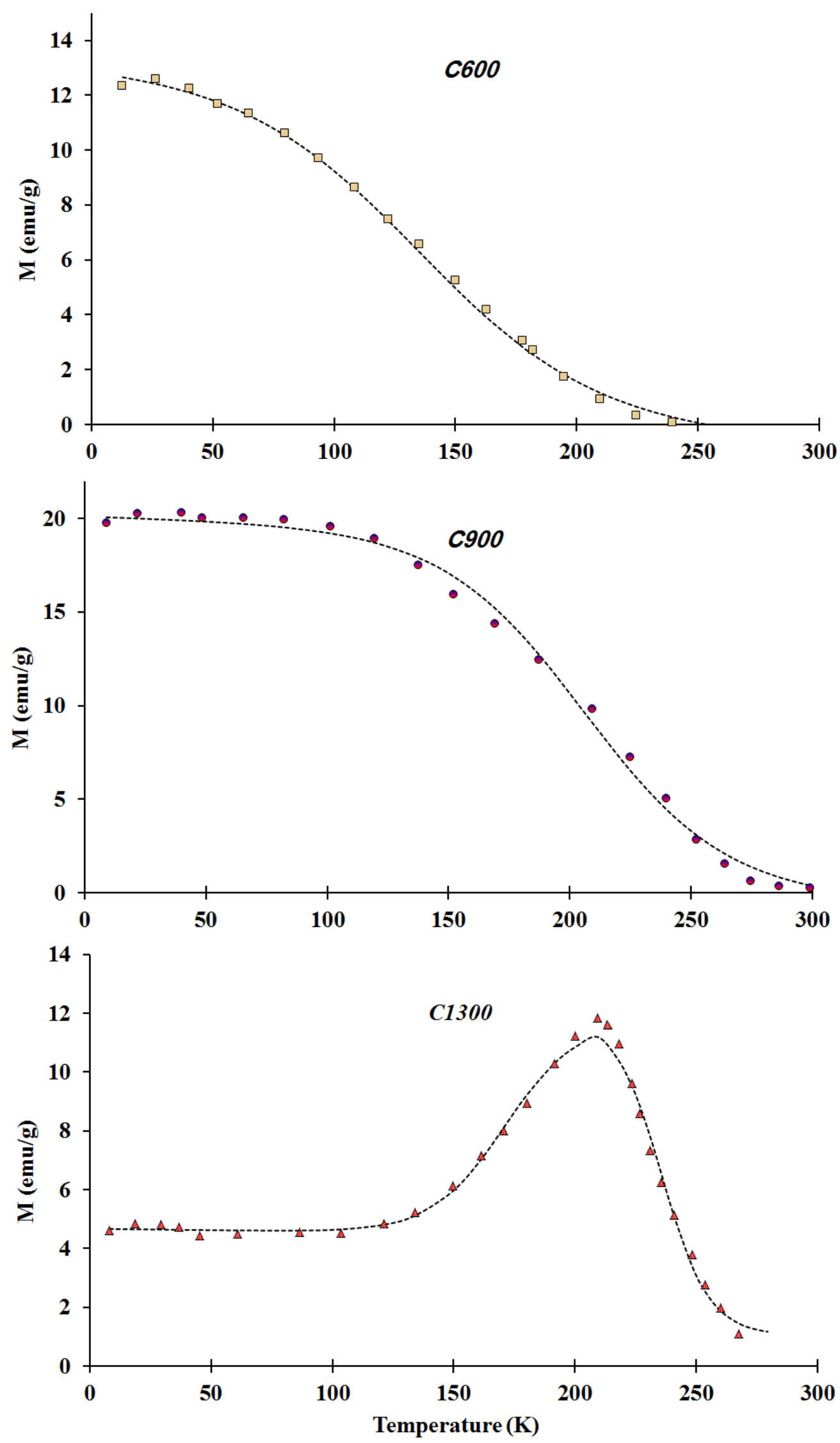

Figure 2: Magnetization vs. temperature for NSMO samples in $\mathrm{H}_{\mathrm{exe}}$ of $0.05 \mathrm{~T}$. The dashed curves are modelled results and symbols represent experimental data from Ref. 49. 


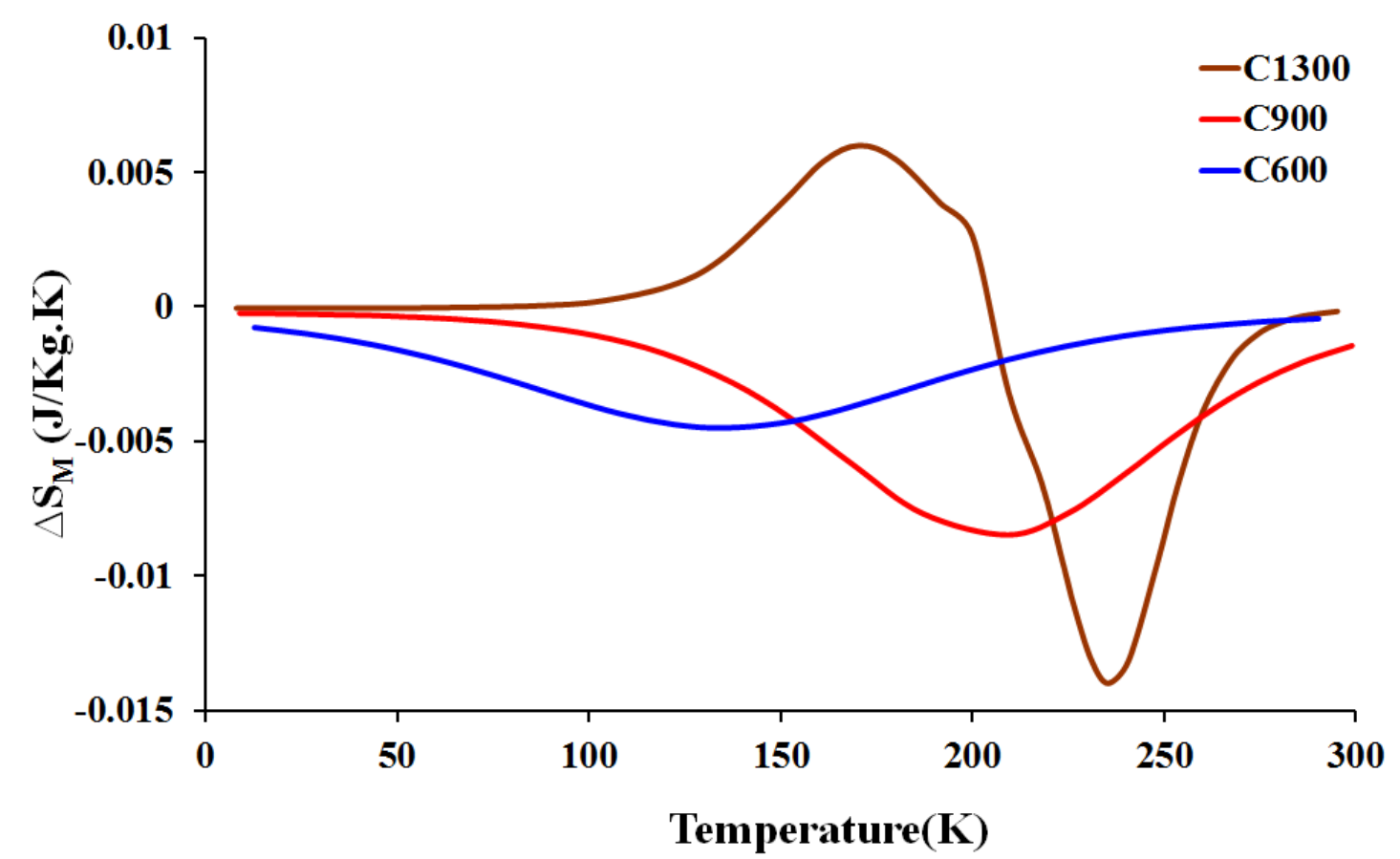

Figure 3: $\Delta S_{M}$ vs. temperature for NSMO samples in $\Delta H$ of $0.05 \mathrm{~T}$. 


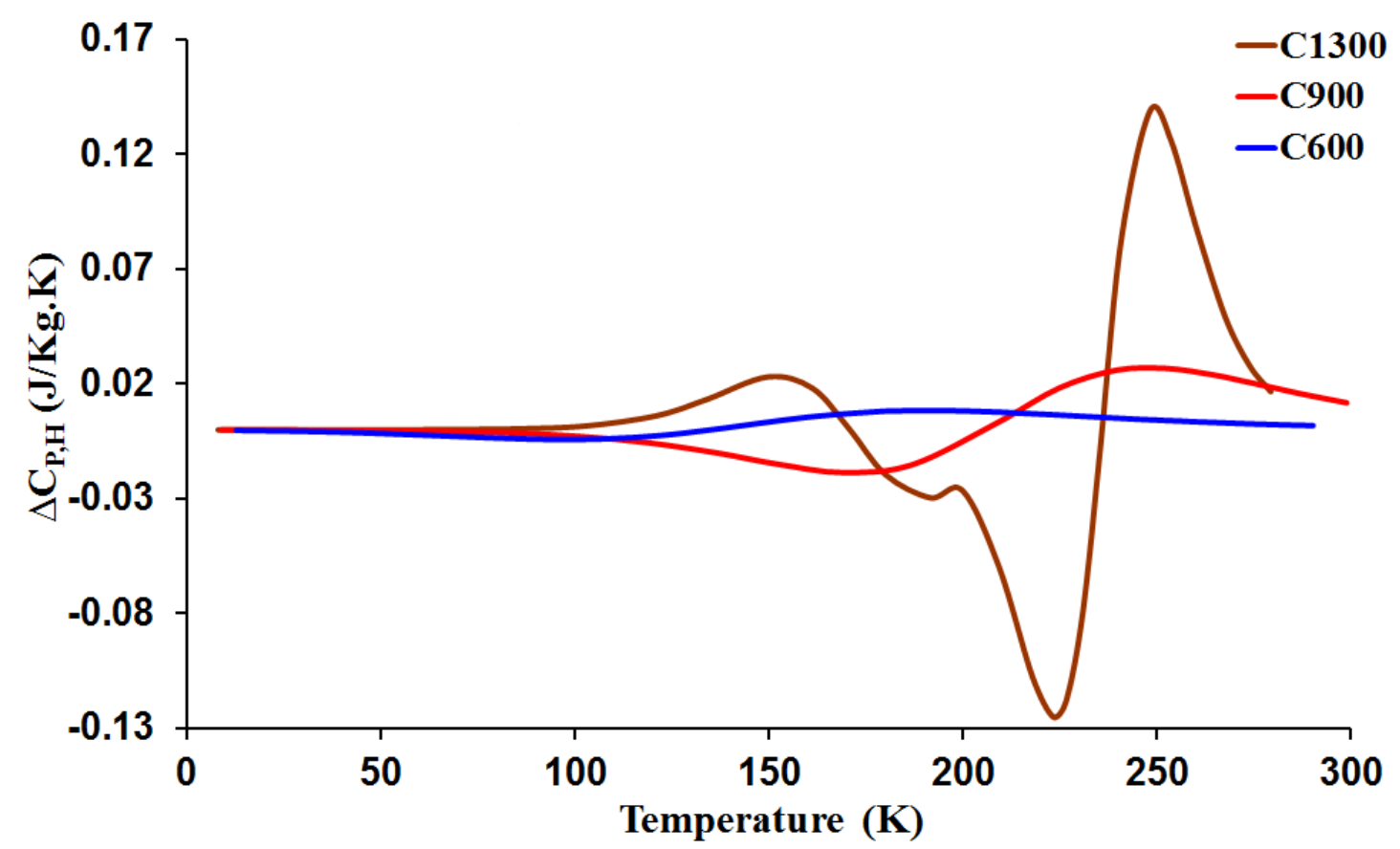

Figure 4: $\Delta \mathrm{C}_{\mathrm{P}, \mathrm{H}}$ vs. temperature for NSMO samples in $\Delta \mathrm{H}$ of $0.05 \mathrm{~T}$. 


\section{$\underline{\text { Tables }}$}

Table I: The predicted values of MC properties for NSMO under $\Delta \mathrm{H}$ of $0.05 \mathrm{~T}$.

\begin{tabular}{cccccc}
\hline Sample & $\begin{array}{c}\left|\Delta \mathrm{S}_{\text {Max }}\right| \\
(\mathrm{J} / \mathrm{Kg} . \mathrm{K})\end{array}$ & $\begin{array}{c}\delta \mathrm{T}_{\mathrm{FWHM}} \\
(\mathrm{K})\end{array}$ & $\begin{array}{c}\mathrm{RCP} \\
(\mathrm{J} / \mathrm{Kg})\end{array}$ & $\begin{array}{c}\Delta \mathrm{C}_{\mathrm{P}, \mathrm{H}(\mathrm{Max})} \\
(\mathrm{J} / \mathrm{Kg} . \mathrm{K})\end{array}$ & $\begin{array}{c}\mathrm{RC} \\
(\mathrm{J} / \mathrm{Kg})\end{array}$ \\
\hline $\mathrm{C} 600$ & 0.0045 & 171 & 0.77 & 0.008 & 0.55 \\
\hline $\mathrm{C} 900$ & 0.0085 & 135 & 1.15 & 0.027 & 0.82 \\
\hline \multirow{2}{*}{$\mathrm{C} 1300$} & \multirow{2}{*}{$0.006,0.014$} & \multirow{2}{*}{69,44} & \multirow{2}{*}{$0.41,0.62$} & $\begin{array}{c}0.023, \\
0.139\end{array}$ & $\begin{array}{c}0.29 \\
0.44\end{array}$ \\
\hline
\end{tabular}

Table II: The values of MC properties for NSMO and other MC materials.

\begin{tabular}{ccccccc}
\hline Composition & $\begin{array}{c}\Delta \mathrm{H} \\
(\mathrm{T})\end{array}$ & $\begin{array}{c}\left|\Delta \mathrm{S}_{\mathrm{Max}}\right| \\
(\mathrm{J} / \mathrm{Kg} . \mathrm{K})\end{array}$ & $\begin{array}{c}\delta \mathrm{T}_{\mathrm{FWHM}} \\
(\mathrm{K})\end{array}$ & $\begin{array}{c}\mathrm{RCP} \\
(\mathrm{J} / \mathrm{Kg})\end{array}$ & $\begin{array}{c}\Delta \mathrm{C}_{\mathrm{P}, \mathrm{H}(\mathrm{Max})} \\
(\mathrm{J} / \mathrm{Kg} . \mathrm{K})\end{array}$ & Ref. \\
\hline $\mathrm{NSMO}$ & 0.05 & $0.0045-0.0085$ & $69-171$ & $0.41-1.15$ & $\begin{array}{c}0.008- \\
0.139\end{array}$ & $\begin{array}{c}\text { This } \\
\text { work }\end{array}$ \\
\hline $\mathrm{BiFe}_{1-x} \mathrm{Zn}_{x} \mathrm{O}_{3}$ & 1 & $0.005-0.006$ & $4.9-6.9$ & $0.27-0.40$ & $0.022-0.038$ & {$[52]$} \\
\hline $\mathrm{Ni}_{58} \mathrm{Fe}_{26} \mathrm{Ga}_{28}$ & $\begin{array}{r}0.2- \\
0.5\end{array}$ & $0.005-0.013$ & $42-73$ & $0.19-0.94$ & $0.04-0.07$ & {$[53]$} \\
\hline $\begin{array}{c}\mathrm{Ge} 0.95 \mathrm{Mn} 0.05 \\
\mathrm{Films}\end{array}$ & 0.1 & $4 \mathrm{E}-7-3.6 \mathrm{E}-6$ & $12.69-17.75$ & $\begin{array}{c}6.3 \mathrm{E}-6-6 \\
0.451 \mathrm{E}-5\end{array}$ & $\begin{array}{c}7.7 \mathrm{E}-6-1.1 \\
\text { E-4 }\end{array}$ & {$[54]$} \\
\hline $\mathrm{NdMnO}_{3}$ & 1 & $3.7 \mathrm{E}-3$ & 6.8 & 0.025 & - & {$[55]$} \\
\hline
\end{tabular}

